\title{
AN APPARATUS FOR DERIVING LAWS OF PENDII,UMS.
}

\section{By Ellison L. Ross, \\ University of Nebraska.}

The apparatus consists essentially of two pendulums-one a second's pendulum and the other of variable length, which are electrically connected to two telegraph sounders in such a manner that one of the sounders will tick every time the second's pendulum passes the central point of its vibration. The other sounder will tick only when both pendulums are at the central pnints of their vibrations at the same instant.

In the accompanying drawings $A$ represents the front view of the second's pendulum, $\mathrm{A}^{\prime}$ the side view of the same. This pendulum differs from the common pendulum only in that it has two rods supporting the bob instead of one. These two rods
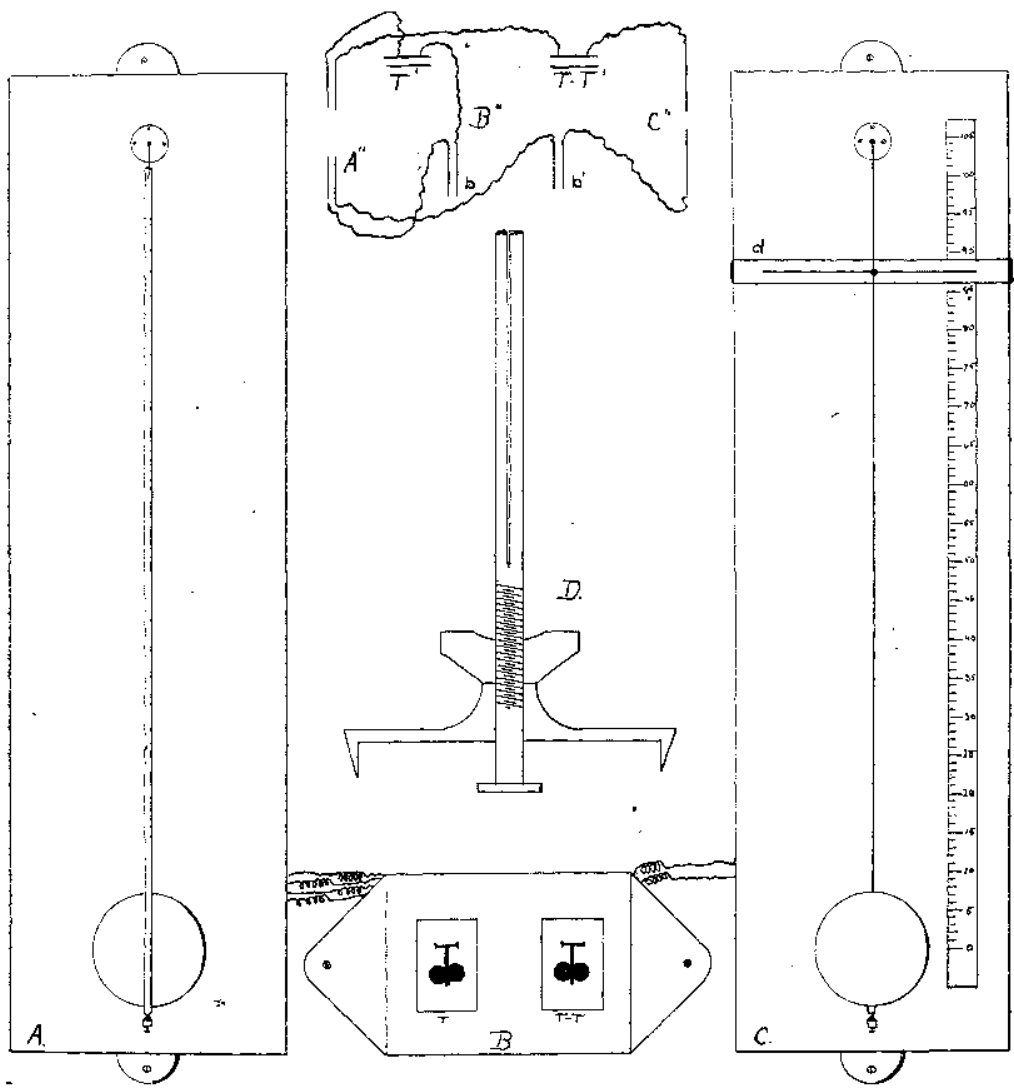
are electrically insulated from each other with hard rubber. The mercury cups are on separate brackets, one curving around the other. Thus A may carry two independent currents which may be closed and broken simultaneously by the vibration of the pendulum.

Figure $\mathrm{C}$ represents the pendulum whose length may be varied. The bob of the pendulum is of the same shape and size as that of the other pendulum and holds a copper rod with a platinum or silver point for the mercury contact. The suspension of the bob is by very thin, clock-spring-steel strips. The manner of suspension is shown in Figure $\mathrm{C}^{\prime}$. Figure $\mathrm{C}^{\prime}$ is the side view of $\mathrm{C}$. The length of the pendulum is varied by a clamp $\mathrm{d}, \mathrm{d}$, and $\mathrm{D}$ which slides in a slot in the standard and is tightened with a thumb-screw. The length of the pendulum may be read from the scale as shown in the figure. Electrical connection is made at the point of suspension at the bracket of the mercury cup.

Figure B represents a box which is just large enough to hold two small common dry cells. On the outside of the box are fastened two telegraph sounders.

The electrical connection between the pendulums, batteries and sounders is shown in Figure $\mathrm{A}^{\prime \prime} \mathrm{B}^{\prime \prime} \mathrm{C}^{\prime \prime}$. Part $\mathrm{A}^{\prime \prime}$ represents the course of the two currents through pendulum $A$. Part $B^{\prime \prime}$ shows the connections that are made in the box connecting sounders ' $\mathrm{T}$ ' and
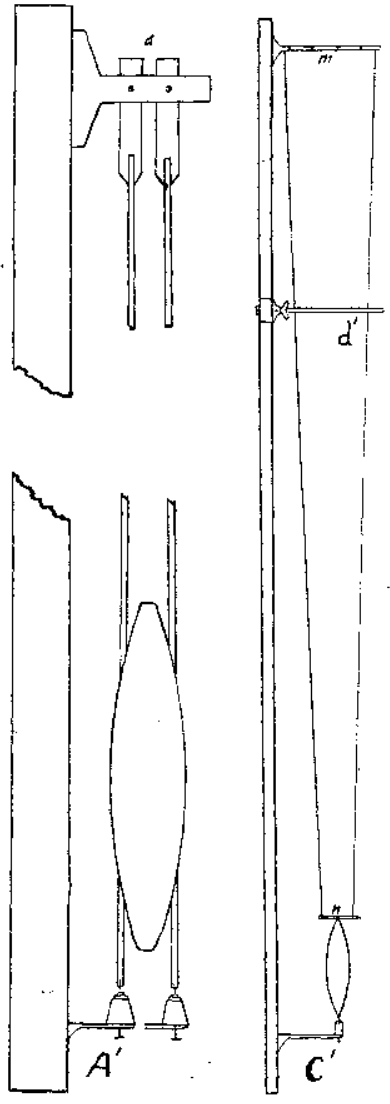
T-T', and cells $b$ and $b^{\prime}$. Part $C^{\prime \prime}$ represents the course of the current through pendulum $\mathrm{C}$.

The whole apparatus is meant to be screwed to the wall.

When the apparatus is in order and both pendulums are in motion, the sounder $T$ will tick every time the lower end of 
second's pendulum passes through the mercury, but sounder T-T will tick only when the ends of second's pendulum and variable pendulum are passing through the mercury cups at the same time. For two operators the derivation of the Law is simple. The length of the variable pendulum is determined and both pendulums are set in motion. When sounder T-T ticks one operator begins to count the ticks of $T$ and the other the number of vibrations of pendulum $C$, both stopping when sounder $T-T$ ticks again. The length may now be changed and the operation repeated.

With this apparatus constructed as described, there will be a possible source of error, but probably small enough to be negligible. This will be due to the fact that the suspension of the variable pendulum, being steel; will not be perfectly pliable, thus making the length of the pendulum not exactly the distance between the center of mass of the pendulum and the lower edge of the clamp. This error may be overcome by using silk cord for suspension and connecting the bob and point of suspension with a fine slack insulated copper wire for carrying the current. But if the apparatus is to be subject to hard general usage, the latter construction is impracticable, as the author has learned from experience.

The essentials of this apparatus were put together by the author while teaching Physics at North Platte, Neb., and while the construction was more crude than that described, High School students had no trouble in deriving the Law comparatively accurately in a short time.

\title{
THE TEACHING OF MATHEMATICS IN CALIFORNIA SEC- ONDARY SCHOOLS.*
}

\author{
By Charles A. Noble, \\ University of California.
}

It is a regrettable fact that a considerable proposition of the students of the University of California enter college without mathematical training sufficient to enable them to profit by a first course in analytic geometry, or in college algebra; that is, without adequate familiarity with the fundamental processes of algebra, or ability to handle the quadratic equation intelligently. The reasons for this deficient training are not far to seek. In many high schools the pupil finishes his algebra with the second year.

*Read before the California Association of Science and Mathematics Teachers. 